\title{
Preparation and study the physical properties of snacks product Chakli by incorporation of gaur gum and gum Arabic
}

\begin{abstract}
Nikhil D. Solanke and Pradip A. Pawar
In this study used of gaur gum and gum arabic in different amounts as independent variables were produced 13 different combinations, two variables, five levels. The purpose of this study was the effect of gaur gum and gum arabic on physical properties of chakli sample using response surface methodology. Multiple regression equations were obtained to describe the effects of each variable on product responses. From this study it was concluded that, optimum solution by numerical optimization for chakli content gaur gum content $1.45 \mathrm{~g}$, gum arabic content $1.82 \mathrm{~g}$ and optimized condition for deep fat fried snacks chakli given best snacks product with positive results that increased in water solubility index and lateral expansion while negative effect on moisture content, shearing force and hygroscopicity.
\end{abstract}

Key Words : Gaur gum, Gum arabic, Water solubility index, Lateral expansion, Moisture content, Shearing force, Hygroscopicity

How to cite this article : Solanke, Nikhil D. and Pawar, Pradip A. (2020). Preparation and study the physical properties of snacks product Chakli by incorporation of gaur gum and gum Arabic. Food Sci. Res. J., 11(2): 70-76, DOI : 10.15740/HAS/FSRJ/11.2/7076.Copyright@2020: Hind Agri-Horticultural Society. 